Cuestiones de filosofía

ISSN: 0123-5095

Vol. 1 - No. 17

Año 2015

pp. $226-238$

\title{
RODRIGO D., DELEUZE Y EL CONTRAPUNTO TEMPORAL
}

\section{Rodrigo D., Deleuze and the temporal counterpoint}

\author{
Andrés Mauricio Cabrera-Díaz* \\ andresmauriciocabrera@gmail.com \\ Universidad del Rosario (Colombia)
}

Fecha de recepción: 11/11/ 2014

Fecha de evaluación: 24/02/2015

Fecha de aprobación: 15/09/2015

\section{Resumen}

El artículo analiza la película Rodrigo D. No Futuro, del director colombiano Víctor Gaviria (Medellín, 1990) ${ }^{1}$, usando algunos conceptos encontrados en el Mil Mesetas, por un lado, y en Imagen-tiempo e Imagen-movimiento, por elotro. En la primera parte, el propósito es hacer uso, en especial, de los conceptos deterritorio, adentro/ afuera, germen y medio, para adentrarse en las imágenes presentadas por la película. En la segunda parte, se propone ir más allá de los conceptos precedentes, para generar un nuevo concepto: contrapunto temporal, tomado de la literatura (Aldous Huxley) y enriquecido con el de imagen-cristal (Deleuze), el cual se refiere, en términos generales, a un tipo de montaje que permite mostrar la forma como diversas historias paralelas se entretejen en torno a algo que es común a todos los personajes del film; en este caso, las fuerzas que son propias del territorio habitado y que cada personaje sujeto a/agente de ellas expresa en términos de No futuro, esto es, como potencia que deviene contra fuerza expresiva.

* Universidad del Rosario. andresmauriciocabrera@gmail.com

1 Se sugiere al lector que no conoce la película acceder al sitio Víctor Gaviria - Rodrigo D. No futuro. (2012), en Youtube: de https://www.youtube.com/watch?v=T1m4tvthI3A 
Palabras clave: Rodrigo D. No futuro, Deleuze, Contrapunto temporal, Territorio.

\begin{abstract}
The paper analysis the Rodrigo D: No future movie, from the Colombian director Víctor Gaviria (Medellin, 1990), using some concepts found in the A Thousand Plateaus (Deleuze \& Guattari), on one hand, and in Image time and Image movement (Deleuze), on the other. In the first part, the purpose is to make use specially of the concepts, territory, inside /outside, germ and media- in order to get in to the images presented by the film. In the second part, the proposalis to go beyond the preceding concepts, in order to generate a new concept: the temporal counterpoint, taken from literature (Aldous Huxley) and enriched with the one of image glass (Deleuze) which refers broadly to a type of assembly thatallows to display, how many parallel stories interweave around something that it is common to all the characters in the film; in this case, the forces that are characteristic of the territory in habited and each character expresses them in terms of No Future, that is how power becomes an expressive counter force.
\end{abstract}

Keywords: Rodrigo D. No future, Deleuze, Temporal Counterpoint, Territory.

\title{
1. El MÉTODO
}

Para Deleuze, el cine no solamente causa nuevas experiencias estéticas, sino que proporciona nuevos espacios para la comprensión de los signos y de las imágenes del pensamiento: "ellos (los directores de cine) piensan con imágenes-movimiento y con imágenes-tiempo, en lugar de conceptos" (Deleuze, 1984, p. 12). Cada gran director de cine dota de un tratamiento particular las imágenes que presenta, las enreda a su propia manera, formando una telaraña compacta que tiene su sello particular. El cine, como dispositivo que relaciona imágenes de múltiples maneras y con diversos propósitos, se constituye como el nicho preciso para conceptualizar sobre su objeto (la imagen). Para el filósofo —o, más bien, el estudiante de filosofía, como es mi caso particular- que quiere pensar el cine, su labor se presenta a la inversa del director de cine: en lugar de pensar a través de la creación de imágenes, reflexiona acerca de la imagen a través de la creación conceptual.

En este caso, el concepto a través del cual quisiera pensar la película es el de contrapunto temporal; sinembargo, para llegar a él propongo transitar las imágenes 
a través de dos conceptos previos que lo componen: el territorio y lo virtual. Por un lado, se tiene que el territorio

es un acto, que afecta a los medios y a los ritmos, que los "territorializa" (...). Está construido con aspectos o porciones de medio. Incluye en sí mismo un medio exterior, un medio interior, un medio intermediario y un medio anexionado. (...) Hay una zona interior de domicilio o de abrigo, una zona exterior de dominio, límites o membranas más o menos retráctiles, zonas intermediarias o incluso neutralizadas, reservas o anexos energéticos (Deleuze, 2002, p. 321).

Por el otro, se tiene lo virtual, que hace referencia a aquella imagen que puede configurarse como posible devenir de la imagen actual que se presenta en el plano. En palabras de Deleuze: "es la imagen virtual que hará cristalizar un medio actualmente amorfo; pero, por la otra, éste debe tener una estructura virtualmente cristalizable con respecto a la cual el germen cumpla ahora el papel de la imagen actual" (1984, p. 105). Ambos conceptos son fundamentales para comprender, al final, la manera en que la potencia del "no futuro" intensifica el contrapunto temporal.

La 'hipótesis' es que Rodrigo D. No Futuro es un filme que parte de la intromisión a cierto medio específico (las comunas de Medellín) a través de múltiples historias relacionadas entre sí de manera más o menos tangencial; para luego constituir un territorio que se sustenta en el diálogo entre tres medios específicos: la comuna (mediointerior), la ciudad (medioexterior) y El Temprano y las terrazas (mediosafuera/ adentro). En ese sentido, la película no presenta un territorio homogéneo, antes bien, se tienen tres espacios atravesados por múltiples fuerzas: la comuna o el barrio, que opera como domicilio y espacio en común de los muchachos; El Temprano, la colina donde coinciden los 'pistolocos' y demás jóvenes marginales dentro de la propia comuna, y la ciudad, espacio por fuera de los límites del barrio. En síntesis, en Rodrigo D. No futuro el territorio se presenta como un constante diálogo de lo que Deleuze llama entre-medios, por lo cual, se configura como un espacio rugoso en el que se inscriben distintas historias sobre/inter/puestas unas a otras constantemente.

\section{TerritorializaCiOneS}

La territorialización implica, en primera medida, el hecho de plasmar un determinado espacio como natal, constitutivo del sujeto ('mi territorio'), disgregado en una multiplicidad de sujetos posibles. El territorio se construye a partir de sujetos que 
poseen, transitan, sufren y moldean el espacio con base en sus propios afectos y posibilidades. Esas posibilidades implican un movimiento abierto, múltiple, y una relación entre medios ${ }^{2}$ que expresa el ritmo del territorio, el cual, a su vez, revierte en la forma como los sujetos 'se sujetan a' ese determinado lugar. El espacio resultante es producto del diálogo transcodificado entre los diversos medios, así como de las múltiples formas y sentidos que los sujetos le otorgan al relacionarse entre sí y con el trazado habitual que les corresponde.

De otra parte, cuando los índices que marcan un territorio "dejan de ser direccionales para devenir dimensionales, cuando dejan de ser funcionales para devenir expresivos" (Deleuzey Guattari, 2002, p. 321) puede establecerse que ha surgido un territorio. Quiere decir que, cuando los elementos (índices) propios de un espacio empiezan a concebirse como constitutivos del estar o del hacer de alguien, manifiestan la relación de un individuo con un determinado ritmo que se ha hecho expresivo, es decir, con un espacio al que se le ha imprimido una "firma", una marca de pertenencia. En ese momento, el espacio es concebido como territorio, como parte natal de un ser que allí comparece.

Hacer de un espacio un territorio implica que ese espacio ha sido apropiado. Que un espacio sea apropiado deriva en que ese lugar se hace eje de una serie de fuerzas específicas que son agenciadas por los sujetos; esto se da en una relación en dos sentidos: en primer término, el código específico de un territorio determina las posibles acciones más o menos codificadas que alguien sujeto de y sujeto $a$ ese espacio puede llegar a realizar. En segundo término, el territorio es el nicho de un determinado cúmulo de fuerzas que son agenciadas por los sujetos. Cada individuo sujeto a un espacio siente la injerencia que dicho lugar tiene sobre él, pudiendo ignorar, transgredir o acatar el código inherente a aquel sitio.

En el caso específico de Rodrigo D. No futuro, se tienen tres espacios diferentes: El Temprano, la Comuna o el barrio como tal, y la frontera compleja de la comuna con la Ciudad (Medellín en toda su extensión). Si, como afirman Deleuzey Guattari, "la transcodificación o la transducción es la manera en que un medio sirve de base a otro, o, al contrario, se establece en otro, se disipa o se constituye en el otro" (2002, p. 320), se puede afirmar que estos tres espacios básicos donde transcurre

2 Una posible definición del diálogo entre medios podría ser la siguiente: conjunto de acciones (entendidas en el sentido extenso del término) emprendidas por un individuo con respecto a un espacio y a aquellos otros individuos que allí comparecen (Deleuze, 2002, p. 320-324). 
la película están en transcodificación constante, y que si bien cada espacio se define por ciertos códigos que inducen a la repetición dentro de una temporalidad propia, a su vez, cada código está expuesto a los demás, en perpetuo estado de traducción y transducción de un código a otro.

\section{La Comuna: medio-interior}

La Comuna se podría presentar inicialmente como el medio-interior, en contraposición a la Ciudad, el medio-exterior. Con medio-interior se hace referencia a la Comuna como lugar de hábitat, de abrigo y cobijo de todos los que allí conviven. El medio exterior, por su parte, reafirma un límite con múltiples fronteras entre la comuna y la ciudad, entre el medio interior y el exterior.

Una de las características principales de la comuna es que se trata de un espacio cerrado, sellado en sí mismo y con unos límites fuertemente marcados. Los que allí habitan se ven inmersos en un espacio en el que todo es conocido, desde el individuo foráneo que arriba al barrio hasta las distintas circunstancias y calamidades de los que allí conviven. De cierto modo, se está ante un panoptismo de la comuna: todo lo que ocurre es conocido por todos. Esto reafirma la relación entre las distintas historias presentadas dentro del filme: todo lo que acontece es conocido, repercute de una u otra manera en los sujetos que conocen esa información. Un ejemplo de ello es el canal de información que manejan los 'pistolocos'y demás maleantes del barrio, o el conocimiento que se tiene de todo el que es parte del 'parche' de la música, igual, la asistencia espontánea y nutrida al sepelio de uno de los 'muchachos'.

Esa vigilancia desde dentro de la comuna se explica, de alguna manera, por una intensa territorialización de la calle como espacio de encuentro, de actividad, de búsqueda, de transacción, de enamoramiento y ocio, especialmente, de los muchachos. Aunque no responden a los hábitos laborales ni a las expectativas escolares, o justo por eso, en su voluntad de afirmar su fuerza en ese medio interior, los 'muchachos' transitan la calle todo el tiempo, día y noche, con su kinesis jovial, pero también inquisitoria y a veces intimidante.Pero si bien sus gestos tienen la pretensión de ser territorializantes, es decir, pretenden interferir directamente en el equilibrio de las fuerzas que en dicho espacio son agenciadas, su propósito siempre queda insatisfecho. Al fin y al cabo las fuerzas se aplican en un entorno cerrado que las agota. Paradójicamente, los muchachos, en su pretensión de dominio, perciben que son las personas que tienen un trabajo afuera de la Comuna las que logran cierta autonomía económica, para ellos y su familia. 
De hecho, es en el desprecio hacia la contemplación de la propia vida y el andar constante por el espacio reafirmando determinados gestos territorializantes (imposición de firmas ${ }^{3}$ sobre el espacio como intentos de apropiación territorial), que se tiene el primer indicio de lo virtual: la imposibilidad de reafirmar 'lo que se es', de pensarse a sí mismo en un mero acto contemplativo, de no poder detenerse a pensar tranquilamente (escenas en la casa, justo antes de dormir), se surten como primer indicio de que aquello que se encuentra dentro de las posibilidades inmediatas de acción subyace a ese resquemor. Dicho de otra manera, lo virtual, tal como es presentado en Rodrigo D: No Futuro, se despliega en la aversión que se siente ante el acto contemplativo, ante el adentro más propio de cada sujeto. El adentro es el primer nicho de análisis de lo virtual ${ }^{4}$. De ahí la sensación compartida de un 'no futuro' que los enerva y los impulsa a salir del medio interior.

Finalmente, la película lo que muestra es cómo esa contra fuerza del "no futuro" deviene en cierto modo en fuerza expresiva, de modo que en vez de repetir las dinámicas y las posibilidades del territorio repetido, los muchachos logran inventar otro tipo de gestos territorializantes, en particular, los que tienen que ver con el encuentro en ElTemprano y con el uso de las terrazas para ensayarse como músicos.

\section{El Temprano y las Terrazas: mediosde un afuera/adentro}

En el caso de Rodrigo D. No futuro, lo constitutivo es el constante diálogo entremedios: los personajes interactúan en relación con un espacio y los sujetos que allí conviven. Si bien la interacción con los múltiples espacios es fundamental, la forma como los personajes dejan sus múltiples huellas territorializantes se da a la manera de un movimiento cinético e incansable, que se contrapone a las reacciones que ocupan al estar en casa. Por un lado, el afuera se presenta como el espacio del caminar y el movimiento constante; por el otro, el adentro es percibido como el momento de la reflexión y la quietud evitada en el transcurso del día. El en casa sirve de signo de algo fugaz y constantemente evitado: el diálogo introspectivo, el adentro propio de cada personaje.

Este concepto se encuentra en el capítulo del Ritornelo: Deleuze y Guattari (2002, pp. 334-336).

4 En este sentido, la forma como las distintas historias se entrecruzan y desarrollan en el filme manifiesta la imposibilidad de un virtual ligado de manera directa al afuera. La relación entre el actual y lo virtual, antes que darse en la línea del adentro hacia elafuera, se gesta en una dirección diametralmente opuesta: en Rodrigo D. No futuro se tiene que el adentro es aquello que apunta hacia lovirtual(es). 
Esta definición del afuera en términos espaciales se complementa, desde el contexto de los individuos y sus posibles virtuales, con un afuera entendido como ligado directamente a la interioridad de los sujetos. En el caso preciso de Rodrigo D: No futuro se puede hablar de un en casa que suscita el diálogo introspectivo tan evitado en el transcurrir normal del día, señala una posibilidad virtual a través de la cual cada personaje percibe la posibilidad de un afuera más cercano: la muerte.

El Temprano es la colina donde se reúnen los 'pistolocos'y demás personajes de dudosa reputación del sector ${ }^{5}$; si bien este es un espacio dentro de la misma comuna, es un espacio desconocido y prohibido para los demás habitantes. En fin, El Temprano es un lugar casi que exclusivo de los jóvenes dedicados a este tipo de actividades delictivas. Logia, barra, combo, banda, son posibles denominaciones, según la energía y los propósitos de los personajes que suben allí. No cualquiera puede entrar, no cualquiera puede tenerlo como un medio-interior. Esta restricción hará del lugar un referente especial para el despliegue de la potencia de "No futuro". Allílos distintos jóvenes se dedican a reafirmar su devenir delictuoso: es el espacio propicio para el entrenamiento y cultivo personal en estas actividades. Como parte constitutiva de las fuerzas que se agencian en este espacio, en El Temprano hay lugar tanto para la reflexión personal aguda, el humor, la crueldad, como para el goce, la traba, el ejercicio, el duelo agonista de puñales. En este espacio, el movimiento atento hacia el afuera del desafío y la seducción sirve de contrapunto íntimo, a veces profundo, a veces burlón, de la quietud reflexiva propia del adentro.

Las terrazas de las casas pueden ser consideradas un espacio clave en la definición del medio que hemos llamado afuera/adentro, por dos razones: una de tipo puramente arquitectónico, y es que efectivamente las terrazas funcionan en las casas de la Comuna como un afuera no construido, normalmente sin paredes, desde donde se ve el conjunto de la ciudad; esa vista por sí misma ya es un afuera; pero también, porque dentro de los múltiples usos es el lugar privilegiado que los jóvenes utilizan para 'parchar', para consumir marihuana, para hacer el amor, pero, sobretodo, en

5 Es curioso lo que Ramiro Meneses, el actor que hace el papel de Rodrigo, opina sobre este lugar: "Tuve un problema con Víctor, porque él insistía en que yo tenía que ir, que eso estaba en el guion y que yo tenía que ir [...] y estar en "El temprano" [...]. Yo le dije que no quería ir, es que yo no robo...métame con los de la música, con ese parche, pero no me meta...es respetable, somos muy distintos. Y me puso a ir, pero con la condición que yo le puse: que yo iba, pero que iba a estar aislado de todos". Ver: Entrevista a Ramiro Meneses. En Youtube (s.f.). Recuperado de https://www.youtube.com/watch?v=dwluMcN-8VI Vista por última vez el martes 13 de mayo de 2014. 
la película, para poner en acción sus bandas de metal o de punk. Es el lugar de encuentro, en un espacio de la casa, pero fuera de ella, un territorio libre, sin control evidente, una puerta de libertad en medio de la precariedad.

Finalmente, y aunque no lo tematizaremos acá, la Ciudad es el medio exterior por excelencia. Una línea de fuga, a veces puramente imaginaria, pero también puede ser una línea de abolición que atrae a los muchachos 'malos' a hacer todo tipo de robos y atracos, con la idea de volver al espacio inmune de la Comuna ${ }^{6}$. Cuando la policía empieza a detener a los muchachos, o cuando la policía de civil o miembros de otras bandas empiezan a perseguirlos para matarlos, y en la huida los muchachos acuden a El Temprano o a las casas altas para refugiarse, es evidente cómo las múltiples historias que se entretejen en cada persecución o muerte se pueden leer también como una forma de interferencia intensa entre los diferentes medios. Este es un elemento fundamental en lo que atañe a la composición del territorio presentado en la película, que muestra la manera como los diferentes medios repercuten en los sujetos, y establece las líneas de fuerza de los planos que se articulan en la película a través del montaje.

\section{EL CONTRAPUNTO TEMPORAL}

El contrapunto es el eje sobre el que se cimienta la polifonía: múltiples voces se tejen alrededor de una superficie musical de manera armónica. En ese sentido, el contrapunto, como categoría musical, hace referencia al "arte de combinar distintas líneas melódicas". Pero por su origen, en el término contrapunto también está implícita la idea de discordancia: "la interacción de concordancia y discordancia entre los diversos factores de la textura musical constituye el elemento contrapuntístico en la música" (Piston, 1998, p. 7).

Ahora, si bien el contrapunto hace referencia a una categoría eminentemente musical, la idea de hacer uso del concepto por fuera de su uso musical ha sido recurrente; un

6 Esta duplicidad en la identidad de los muchachos, que parecen disociados entre la vida cotidiana y los 'trabajos' que implican robo o sicariato, se expresa en el plano actoral en los comentarios de Víctor Gaviria acerca del complejo carácter de los actores 'naturales' de su película: "el actor natural te anuncia quién es, pero te esconde quién es [...]. Como sabe que lo que está mostrando es verdad [...]el actor natural anuncia y sugiere pero también esconde" Ver: Entrevista a Víctor Gaviria en el marco de unas conferencias sobre cine en la UNAM, año 2012. En Youtube (2012). Recuperado dehttps://www.youtube.com/ watch? $\mathrm{v}=\mathrm{XH} 4 \operatorname{VanNTmZc}$ (12 de mayo de 2014). 
caso canónico de su uso literario es justamente la novela Contrapunto, de Aldous Huxley. Formalmente, la novela se construye sobre la base de múltiples personajes relacionados entre sí de múltiples maneras; en palabras del propio Huxley:

La musicalización de la novela. No a la manera simbolista, subordinando el sentido del sonido (...). Pero sí en gran escala, en la construcción (...). Los cambios, las bruscas transiciones (...). Se expone un tema: luego se desarrolla, se cambia, se deforma imperceptiblemente hasta que, aunque permaneciendo reconociblemente el mismo, se ha hecho totalmente diferente. (...) Poner esto en una novela. ¿Cómo? Las transiciones bruscas no presentan ninguna dificultad. Todo lo que se necesita es un número suficiente de personajes y de intrigas paralelas, argumentos de contrapunto. Mientras Jones asesina a su esposa, Smith empuja el cochecillo del niño en el parque. Se alternan los temas" (1983, p. 300).

No es difícil imaginar cómo estos descubrimientos entraron al cine por la habilidad literaria de los guionistas, que se traduce luego en términos de montaje, pero hay elementos propios dela imagen-cine planteados por Deleuze en torno a la imagencristal que puede hacer más interesante el concepto de contrapunto temporal y su perspectiva de análisis.

Con imagen-cristal,Deleuze se refiere a la forma como, dentro de la imagen cinematográfica, ciertas posibilidades que ya se han constituidocomo actuales (es decir, acciones o elementos que ocurren o están ocurriendo en ese momento dentro del filme) se disuelven en una nueva acción o episodio fílmico que se genera gracias a lo que la anterior imagen-actual permitía como posible. Este movimiento de lo actual a lo futuro con base en las posibilidades de la imagen presente en el plano cinematográfico (imagen actual) es una manera de entender lo que Deleuze explora como relación entre "lo actual y lo virtual". En síntesis, lo actual se refiere a aquellas posibilidades preexistentes que sirven de base a un cúmulo denuevas posibilidades dentro del filme (lo virtual). Al cambiar de fotograma, la película redirige la mirada hacia un nuevo actual que antes se tenía tan solo como posibilidad virtual. De esta manera, las imágenes se suceden las unas a las otras, tejiendo el entramado del filme.

El elemento cristalino hace referencia al componente reflectivo de las imágenes. De hecho, la imagen que acaece (imagen actual que anteriormente era virtual) no se extingue del todo; antes bien, permanece como sustento de las imágenes que se siguen sucediendo. De no ser así, los distintos planos que se presentan uno tras otro 
en la pantalla no tendrían relación alguna: serían imágenes inconexas que se introducirían sobre un tiempo vacío, destinado a ser rellenado. De hecho, las imágenes mantienen una conexión de modo que, aunque no tengan continuidad temporal o espacial,o justo por eso,se suceden sin mayor conflicto, sustentadas en una relación de intercambio constante: "el cristal no cesa de intercambiar las dos imágenes distintas que lo constituyen, la imagen actual del presente que pasa y la imagen virtual del pasado que se conserva: distintas y sin embargo indiscernibles" (Deleuze, 1990, p. 114).

A medida que las imágenes se van entretejiendo entre actuales y virtuales, lentamente se configura un medio. El film se compone de imágenes que, al entretejerse, constituyen un medio complejo que sirve de eje de continuidad dentro de la lógica actual/virtual que le corresponde a cada película.Para Deleuze, hay dos condiciones que hacen posible esa cadena entre lo virtual y lo actual: "(por una parte) es la imagen virtual (germen) que hará cristalizar un medio actualmente amorfo; pero, por la otra, éste debe tener una estructura virtualmente cristalizable con respecto a la cual el germen cumpla ahora el papel de la imagen actual"' (Deleuze, 1990, p. 105).

En lo que atañe a Rodrigo D: No futuro, cada personaje desarrolla una historia que se ciñe al tiempo cronológico que cierra temporalmente la película, sin retenciones ni proyecciones, ceñida al continuum del presente propio de los muchachos. A su vez, cada historia se entreteje alrededor de múltiples elementos comunes que sirven para nutrir la relación dentro de la Comuna: la coincidencia generacional, la marginación dentro de la propia comuna, la forma de ocupar la calle, los encuentros festivos, los negocios comunes, el 'toque' en la terraza, la visita a El Temprano. Esto genera un cúmulo de intrigas paralelas que parecen insustanciales hasta que aparece la muerte y la desaparición como las formas más evidentes de 'no futuro'.

El contrapunto temporal hace referencia a este fenómeno en específico: al hecho de que las historias paralelas se entretejen en torno a algo que es común a todos. Un pliegue adicional de este tejido es el que produce el estar en casa, la quietud normalizante, a veces introspectiva, que contrasta con la velocidad y las intensidades del afuera, donde suceden los cruces, intercambios, los planes, los desafíos. En ese adentro, siempre transitorio, cada uno de los personajes parece conectado consigo mismo, con su propia (im)potencia. Para remarcar esos momentos, la película recurre a los primeros planos, magnificando el rostro, fuera de la acción, de modo que lo que germina en el medio, que es la Comuna, quede reducido al suspenso del rostro como imagen-virtual, impredecible. 
Los primeros planos al rostro marcan una potencia, una fuerza que recorre a los individuos de manera constante en su devenir, pero que pocas veces es expresada claramente ${ }^{7}$. Esa potencia se materializa en una experiencia afectiva que, en palabras de Deleuze, "más que concebida, es sentida: concierne a lo nuevo en la experiencia, lo fresco, fugaz y sin embargo eterno". En ese sentido, el sentimiento de "No futuro", más que ser apresable en una categoría estática y fija, remite a esa potencia constitutiva de la vida individual. Sin ser plenamente consciente, la potencia finalmente es la que crea una especie de medio de medios, un germen de lo posible, una tensión permanente entre el adentro y las múltiples incursiones en el afuera.

En el bordado común de las historias de cada uno de los muchachos, puede verse cómo esta potencia propia del "No Futuro", que se expresa cada vez en la imagenafección singularizada, termina por materializarse de manera más evidente en la muerte del metalero, en el asesinato de Ramón, en el suicido de Rodrido D. Sin embargo, ciertamente podrían plantearse otras circunstancias en las que esa potencia deviene en fuerza expresiva: la pelea con puñales en El Temprano, las correrías nocturnas sin rumbo fijo, pero atraídas por el deseo de muertes, la rabia delirante de la voz y la batería en lo toques de metal y punk en la terraza.

\section{Conclusiones}

Los personajes de Rodrigo D. No futuro no son receptáculos pasivos de categorías ligadas al análisis de un contexto de marginación social específico, más bien se presentan como sujetos a un territorio, la Comuna, cuyas fuerzas son transformadas por el destino fatal de cada uno. Hemos dicho que el contrapunto va tejiendo las distintas historias, pero en relación con el medio como germen se puede hablar de un contrapunto fundamental entre la quietud del adentro, del hábito familiar y la introspección, y el movimiento siempre ansioso, impredecible, en busca de la vida/ muerte que llama desde afuera (medios territoriales). Amedida que la historia se desarrolla, ese contrapunto hace que las imágenes actuales, en su frenesí, remitan

7 Deleuze afirma que es gracias al primer plano que los tres recursos del Rostro se anulan. Estos son: Individuante (distingue o caracteriza a cada cual), relacional o comunicante (asegura no solo la comunicación entre dos personas, sino también para una misma persona, el acuerdo interior entre su carácter y su rol), y socializante (manifiesta un rol social) (Deleuze, 1984, p. 146-147).

8 Este concepto es el de la "primeidad", elemento constitutivo de la imagen-afección (Deleuze, 1984, p. 145). 
cada vez más a un virtual en cuyo trasfondo subyacen en un fondo oscuro, indeterminable, que remite al adentro de los personajes (medio introspectivo). En el intento de dilucidar la relación específica que une a ambos medios, hemos puesto en primer plano los conceptos de contrapunto temporal y virtualidad.

Lo dicho hasta ahora arroja una conclusión fundamental: el desgaste delelemento afectivo propio de los planos de la quietud introspectiva del en casa, que Deleuze llamaría primeidad, termina por hacer que la potencia del "No Futuro" -que acaece de manera fugaz, pero que es un signo recurrente y constitutivo de la vida de estos jóvenes- una fuerza expresiva. El devenir de esa fuerza se realiza modificando el estado de cosas preexistente. Para Deleuze, "la primera figura de la secundeidad es aquella en que las cualidades-potencias devienen fuerzas, es decir, se actualizan en estados de cosas particulares, espacios-tiempos determinados, medios geográficos e históricos, agentes colectivas o personas individuales. Ahí nace la imagen-acción" (1984).

Lo que era meramente una potencia que se hacía manifiesta de manera difusa en una imagen no actualizada, ahora se hace objeto de actualización en circunstancias que, excepto el suicidio del protagonista, normalmente desde afuera llamamos delictivas. La impotencia frente al afuera del entorno urbano, moderno, perceptivo, se traduce en un afuera ligado directamente a la interioridad de los sujetos. La potenciadel "No Futuro" deviene fuerza, y con ello repercute directamente en la realidad real y en la realidad cinematográfica. En ese sentido el drama también es documental, y no es una coincidencia que los actores hayan muerto al poco tiempo de terminada la película.

La comprensión profunda que brinda la película sobre la potencia del "No Futuro" se desprende de la multiplicidad de historias y sujetos entretejidos por el territorio en común. El contrapunto temporales el tipo de montaje que permite que se presente este diálogo polifónico entre diferentes historias que, si al inicio parecía querer narrar la historia de un muchacho en búsqueda de una batería, termina por narrar el devenir fuerza de la potencia del "No Futuro" o, si se quiere, la contrafuerza de cada historia particular. 


\section{REFERENCIAS}

Calle, G. y Trujillo, A. (productores) y Gaviria, V. (director). (1990). Rodrigo D: No futuro [cinta cinematográfica]. Colombia: Compañía de Fomento Cinematográfico - FOCINE.

Deleuze, G (1984). Estudios sobre cine I: Imagen-Movimiento. Barcelona: Paidós. Deleuze, G. (1990). Estudios sobre cine II: Imagen-Tiempo. Barcelona: Paidós.

Deleuze, G. y Guattari, F. (2002).Mil Mesetas. Barcelona: Pre-Textos.

Gaviria, V. (2012). "Rodrigo D no futuro". En: Youtube. Recuperado de https:// www.youtube.com/watch? $\mathrm{v}=\mathrm{T} 1 \mathrm{~m} 4 \mathrm{tvth} \mathrm{3} \mathrm{A}$

Huxley, A. (1983). Contrapunto. Colombia: Oveja Negra-Seix Barral.

Meneses, R. (s.f.). En: Youtube. Recuperado de https://www.youtube.com/ watch? $\mathrm{v}=\mathrm{dwluMcN}-8 \mathrm{VI}$

Piston, W. (1998). Contrapunto. España: Spanpress Universitaria. 